\title{
SOBRE ARTESANIA E CURRÍCULOS PENSADOSPRATICADOS: QUANDO TUDO FOGE A NORMA
}

Rafael Marques Gonçalves ${ }^{\mathrm{i}}$

\begin{abstract}
Resumo: A proposta deste artigo é apresentar parte de uma pesquisa de doutorado, que entende que, por meio de conversas, podemos aprender a compreender o cotidiano pesquisado. As ações investigativas são desenvolvidas na perspectiva das pesquisas no/do/com o cotidiano, lançando mão de conversas com um grupo de professoras, com as quais são buscados as diferentes formas de percebersentir as realidades sociais a partir de sua complexidade e dos inúmeros (des)encontros entre o falado, o percebido e o praticado. O recorte aqui realizado diz respeito à relação daquilo que as professoras fazem em seus cotidianos, ou seja, seus modos de fazer, e as propostas que as orientam, incluindo os materiais didáticos que recebem. Assim, ao compreender as bricolagens praticadas nos cotidianos das escolas, podemos perceber como os processos de criação curricular trazem à tona o uso das regras e produtos que foram dados para consumo das professoras inscritas como autoras, como criadoras de currículos pensadospraticados nas relações politicopráticas que tecem e atuam cotidianamente nos seus espaçostempos.
\end{abstract}

Palavras-chave: cotidiano escolar; currículos praticados; conversas; narrativas.

\section{ON HANDICRAFTS AND PRACTICED THOUGHT CURRICULATES: WHEN IT ALL FOGS THE STANDARD}

\begin{abstract}
The purpose of this article is to present part of a doctoral research, which understands that through conversations, we can learn to understand the searched everyday. The investigative actions are developed in the perspective of the researches in the / of / with the daily life, giving place to conversations with a group of teachers, with whom the different ways of perceiving and feeling the social realities are sought from their complexity and the numerous Disagreements between the spoken, the perceived and the practiced. The clipping here refers to the relation of what teachers do in their daily lives, that is, their ways of doing, and the proposals that guide them, including the didactic materials they receive. Thus, by understanding the practices practiced in the daily life of schools, we can see how the processes of curricular creation bring to light the use of the rules and products that were given for the consumption of the teachers enrolled as authors, as creators of thoughtful curricula in the politico practice relations that weave And act daily in their spaces.
\end{abstract}

Keywords: school everyday; Curriculum practiced; Conversations; Narratives. 
$O$ artífice frequentemente enfrenta padrões objetivos de excelência que são conflitantes; o desejo de fazer alguma coisa bem pelo simples prazer da coisa benfeita pode ser comprometido por pressões competitivas ou obsessões. $O$ artífice explora essas dimensões de habilidade, empenho e avaliação de um jeito específico. Focaliza a relação íntima

entre a mão e a cabeça (SENNET, 2012a, p. 19-20)

Sigo minha trajetória acadêmica desenvolvendo pesquisas que buscam na criação curricular cotidiana, as bricolagens docentes/discentes a partir de diálogos e embates com normas curriculares, circunstâncias locais, suas possibilidades e limites, saberes plurais e culturas locais, no fito de tecer redes de fazeressaberes que considero pertinentes para compreender o cotidiano escolar e sua produção científica atual.

Nesse processo de compreensão daquilo que existe de criação e reinvenção na produção das bricolagens cotidianas que tecem cada cotidiano em sua riqueza própria e em sua especificidade, identifico processos subversivos, criativos, emancipatórios de criação curricular. Sigo, assim, entendendo que essa identificação permite desinvisibilizar (SANTOS, 2004) existências tornadas invisíveis pelos processos formais de compreensão dos cotidianos das escolas e que nelas só percebe o que falta ou o que segue às normas formais, frequentemente em conflito com os saberesfazeres locais e seus possíveis.

Em minha pesquisa de doutorado venho buscando, por meio da observação/participação nos cotidianos escolares, conversas com seus praticantespensantes em que aquilo é oferecido com base em suas ações/narrativas nossos parceiros de pesquisa - jamais objetificados, sempre sujeitos com os quais dialogamos em processos de aprendizagem mútua - sobre seus cotidianos, conflitos, prazeres, fazeressaberes e interrogações.

Portanto, neste texto abordo para debate parte da pesquisa, em fase final de elaboração, a qual entende que, por meio de conversas, podemos aprender a compreender o cotidiano pesquisado. A pesquisa foi desenvolvida empiricamente por meio de conversas com um grupo de professoras e a parte dela que aqui se encontra diz respeito à relação daquilo que fazem em seus cotidianos e as propostas que as orientam, incluindo os materiais didáticos que recebem.

Nessas conversas do grupo, as professoras relataram que acham válidas as propostas didáticas encontradas em livros didáticos e paradidáticos, sobretudo quando trazem dicas de jogos, atividades, material rico em cores e etc., mas assumem que também "não dá para seguir à risca" nada do que está apontado nos materiais, pois os alunos nem sempre conseguem seguir o 
conteúdo proposto. Por isso surge, com frequência, a necessidade de buscar mais e mais propostas.

\section{Do mergulho}

Para o desenvolvimento da pesquisa, recorro à perspectiva teórico-políticaepistemológica-metodológica (OLIVEIRA; SGARBI, 2011) que me anima nessa tessitura e que vem me levando a crer na possibilidade de vislumbrar os caminhos possíveis das alternativas e potências das práticas cotidianas.

Pais (2003) afirma que a legitimação de modelos e verdades científicas dar-se-á pelo fato de que ambos pressupõem aperfeiçoar performances que fabricam uma dada realidade social, com base em estatutos e teorias que, na maioria das vezes, pairam sobre a sociedade como hábitos e totens científicos, a partir dos quais a própria ciência traduz-se em representações coletivas de uma aparente face do cotidiano.

$\mathrm{Na}$ contramão desse modelo e de tendências fixas, a sociologia do cotidiano procura usar a teoria de maneira distinta, principalmente pelo fato de que teoria e prática de pesquisa são indissociáveis, ou seja, todo e qualquer pressuposto teórico que anime certa pesquisa vai partir do cotidiano e das suas diferentes noções e nuances. Assim, como vias de desvio, é preciso, para estarmos atentos a possíveis brechas que os saberes, antes alinhados de maneira universal, possam ser abertos para criarem-se espaços, outras brechas e intervalos no campo dos saberes desalinhados.

Daí que a sociologia do cotidiano é, sobretudo, um espaçotempo de produção de sentidos que comumente estão ligados a detalhes que fomentam a impossibilidade de estabelecer padrões de uma totalidade nas localidades do cotidiano e que ainda fundamentam as pesquisas com os cotidianos.

Alves (2008), quando formula as noções que embasam esta outra forma de se pesquisar, assinala a importância que o sentimento do mundo possui para nos lançarmos a buscar aquilo que nos movimenta e impulsiona a percebersentir a pluralidade da vida cotidiana, suas trivialidades, seus conhecimentos, cheiros, sons etc. Como premissa na busca por caminhos possíveis para encarar a pesquisa em educação, contrariamente à formação até então aprendida e desenvolvida, o sentimento, enquanto algo que nos oportuniza a enxergar outras maneiras de fazerpensar o cotidiano escolar, incluindo, nesse sentido, o cotidiano da pesquisa, traz consigo a necessidade de sermos capazes de sentir um pouco de quase tudo o que de banal e rotineiro nos passa, sabendo que é nesse movimento que encontramos a tessitura de conhecimentos em rede, de potências e alternativas. 
Para tal é que a autora nos apresenta a necessidade do mergulho na "realidade" vividapesquisada, que se fez necessário com o acompanhamento do anteriormente dito sentimento do mundo, que, como premissa metodológica, aponta ser primordial não apenas olhar o mundo, e sim senti-lo, em todas as suas nuances de possibilidades e pontos de vista, estando atento a tudo o que nele se passa, se acredita, se repete, se tece, se (re)significa, e rememorando Pais (2003), sentir o cotidiano e submerso em suas águas, às vezes turvas, buscar quase tudo o que nele se passou, mesmo quando nada aparentemente tenha se passado.

Neste sentido, em março de 2016 realizo mais um mergulho no cotidiano escolar em um encontro com as professoras, estruturado a partir de uma roda de conversas, em uma noite trirriense ${ }^{i i}$ tipicamente abafada do verão. Pauta do dia: "currículos e as práticas cotidianas", temática motivada pelas conversas que tivemos no encontro anterior, quando conversávamos sobre quais percepções tínhamos sobre currículos e cotidiano escolar.

Contudo, não apenas motivados pelas narrativas anteriores, as professoras estavam ansiosas para narrar sobre situações que ocorreram dias depois, do nosso primeiro encontro, nas escolas e que envolveram a discussão curricular que vinha sendo realizada pelos Supervisores Pedagógicos.

Desde o início do ano de 2016, a secretaria de educação vinha buscando promover a reestruturação curricular e suas orientações. O motivo, segundo a fala de uma das técnicas da $\mathrm{SE}^{\mathrm{iii}}$, se ligava ao fato de que o documento existente já não mais refletia a realidade da educação municipal, porque era datado da década de 1990.

Nas conversas do grupo, as professoras relataram que acham válidas as propostas didáticas encontradas em livros didáticos e paradidáticos, sobretudo quando trazem dicas de jogos, atividades, material rico em cores e etc., mas assumem que também "não dá para seguir à risca" nada do que está apontado nos materiais, pois os alunos sempre conseguem seguir o conteúdo proposto. Por isso surge, com frequência, a necessidade de buscar mais e mais propostas.

Profa. Rita - Essa semana na minha turma eu usei um texto do livro didático da Magda Soares, a história era linda, apesar de um pouco grande pra turma, os alunos não deram conta e quando comecei a fazer, tentar né, a interpretação de texto oral eles começaram a contar uma situação que eles tinham vivido na rua deles. A história deles até tinha a ver com a do livro, se fosse outro tempo eu tinha chamado a atenção, tentado de todas as formas retornar ao livro didático, mas o que eu fiz foi dar valor ao que eles estavam trazendo... 
Profa. Verônica - A gente sempre precisa buscar outras coisas, mesmo que seja muito rico em desenhos e histórias, os meus alunos, às vezes, não conseguem também entender o texto, ou então estão motivados por outra coisa que aconteceu na comunidade deles. Pra mim o governo e essas editoras tinham mesmo era que ir dar aula pra ver como tudo acontece de verdade antes de fazer qualquer coisa...

Dialogando com essas narrativas, trazidas de forma introdutória ao estudo do material empírico da pesquisa, percebo que as professoras não se portam de maneira passiva quando submetidas à imposição de propostas externas, elas bem sabem o quanto sua realidade não está estampada no material que chega à escola que não contempla a riqueza da diversidade de saberes e as redes de conhecimentos tecidas e presentes no cotidiano escolar.

Aqui podemos trazer à tona a contribuição de Certeau (1994) quando defende que o "homem ordinário ${ }^{\mathrm{iv} "}$ remodela suas ações e artes de fazer, através das suas astúcias, perspectiva que pode ser compreendida como outra forma de interpretação das práticas culturais contemporâneas. Neste sentido, posso lançar mão da noção de consumo, na medida em que as professoras ressiginificam suas ações e usam aquilo que lhes é dado para consumo de outras maneiras, ou seja, repensam, criam astúcias para lidar com textos e propostas curriculares pensadas longe de suas realidades e possibilidades de trabalho com sua comunidade escolar.

A uma produção racionalizada, expansionista além de centralizada, barulhenta e espetacular, corresponde outra produção, qualificada de consumo: esta é astuciosa, é dispersa, mas ao mesmo tempo ela se insinua ubiquamente silenciosa e quase invisível, pois não se faz notar com produtos próprios, mas nas maneiras de empregar os produtos impostos por uma ordem econômica dominante. (CERTEAU, 1994, p.39)

Ou seja, a narrativa que surge da conversa entre as professoras permite perceber como os sujeitos comuns fazem uso de "suas astúcias, seu esfarelamento em conformidade com as ocasiões, suas 'piratarias', sua clandestinidade, seu murmúrio incansável, em sua uma quaseinvisibilidade" (CERTEAU, 1994, p. 94).

Percebendo o cotidiano escolar como área de produção de ações, como espaçotempo de permanente negociação, reinvenção, das artes de fazer, entendo que isso significa que os sujeitos praticantes do cotidiano usam as propostas didáticas externas, buscando compreender a necessidade de praticar suas astúcias e valorizar outras redes de conhecimentos, o que vai ao 
encontro de um discurso contra-hegemônico em relação ao modelo de escola e de ação pedagógica que os percebe como meros consumidores daquilo que é produzido externamente.

Essa negociação de sentidos e a re(invenção) dos currículos, criando os currículos pensadospraticados, são possíveis em virtude dos usos que os praticantes fazem dos produtos e das regras oferecidas para seu consumo (CERTEAU, 1994). Contudo, segundo o autor, os mecanismos de resistência sempre foram exercício de longo tempo e vão sendo definidos de acordo com cada contexto e da inserção dos praticantes nele. Ou seja, os usos sempre serão realizados de formas distintas, e levariam em consideração a cultura do cotidiano escolar.

Profa. Bianca: - Verdade seja dita, a gente tem que rebolar é muito com todas as dificuldades e falta de material. No meu ponto de vista a gente acaba é refazendo tudo o que mandam. Eles pensam de um jeito e a gente faz de outro...(risos). É muito mais legal quando consigo fazer alguma coisa com a minha turma que eu criei, mesmo que tenha tirado a ideia do livro, mas fomos eu e eles que fizemos, do nosso jeito. E quando dá pra fazer com outra turma? Nossa, fica mais legal ainda!! Lembra, Verônica, ano passado quando fizemos o projeto do trânsito?.

Profa. Verônica: - O que eu mais gosto de fazer é pegar esses materiais e guardar.(risos). Guardo com carinho tudo, mas antes eu recorto um monte de coisas que eu acho que dê pra usar. Ah gente, é isso mesmo, tudo é lindo, muito lindo, mas recortar e usar de outra maneira é melhor (risos). Ano passado na escola fizemos o projeto do trânsito, que a Bianca falou, tinham mandado pra escola um monte de orientações, mas só que do jeito que estava eles tinham pensado que os alunos eram de escola particular. Gente, nossos alunos, pelo menos a maioria deles, andam a pé e usam ônibus, mas quase não saem do bairro que moram. $O$ que nós fizemos foi juntar com todas as outras professoras e pensar tudo de outra maneira, próxima da nossa realidade.

Do excerto narrativo acima, posso apreender que nas relações estabelecidas nas/das artes de fazer nos/dos cotidianos, a sua própria rede institucional vai estar permeada, mesmo que de forma transgressiva, pelo estilo peculiar de cada uma, nas trocas, nas invenções e na resistência. Substituindo a ideia de práticas de consumo, comuns e rotineiras, as "maneiras de fazer" são habitadas pela vontade e pelo desejo de produzir um conhecimento autoral, gerando, com isso, currículos pensadospraticados, cotidianamente.

A conversa das professoras traz à tona como estas buscam (re)pensar suas práticas e (re)inventar suas artes de fazer cotidianas. Do meu ponto de vista, elas se colocam como artesãs, 
como artífices (SENNETa, 2012) que manuseiam material bruto para fazer arte, seja em suas individualidades ou coletividades cotidianas.

Neste sentido, as maneiras de fazer dos praticantes vão aliar-se a outras regras diferentes daquelas da produção e do consumo oficiais, possibilitando novas maneiras de utilizar a ordem regulatória, como na bricolagem do material do projeto de trânsito. Para além do consumo puro e simples, os praticantes desenvolvem ações, fabricam formas alternativas de uso, tornando-se produtores/autores, disseminam alternativas, manipulando, ao seu modo, os produtos e as regras, mesmo que de modo invisível e marginal.

No desenvolvimento da pesquisa, o que me interessa é fazer emergir as práticas sociais que produzem saberes, as práticas curriculares que produzem currículos outros e sobretudo o caráter coletivo de ambas. No caso específico desta pesquisa, as práticas curriculares assumem o processo de reconstrução permanente dos textos políticos e um dos meus objetivos é compreender como estas articulações acontecem, como são produzidas as micropolíticas de currículo.

Por micropolíticas entendo o contexto das práticas (BALL, 2001), tendo em vista que assumo o currículo como produção cultural, ou seja, é no contexto das práticas que as políticas macro, no caso da pesquisa as políticas curriculares, são ressignificadas, perpassam por sentidos de disputa e negociações. Contudo como bem lembra Macedo e Frangella (2008, p. 53):

a noção de política de currículo como texto e discurso, elaborada num ciclo que envolve múltiplos contextos, nos permite compreendê-la na ambivalência, atentando para que, se a análise do papel do Estado não pode ser suprimida, ela precisa se dar na articulação com processos micropolíticos presentes não só na esfera estatal, mas em outros contextos.

Assim a micropolítica de currículo vai estar associada uma instância fragmentária, um espaçotempo específico significado pelas rotas de fuga, pelas artes de fazer e de resistência dos currículos pensadospraticados nos cotidianos escolares, ou seja, os currículos que se inscrevem e formam outras redes no contexto das práticas.

Retomando a noção de que a produção do currículo é uma criação cotidiana (OLIVEIRA, 2012), percebemos também o quanto o currículo é uma construção cultural atravessada por relações de poder. Portanto, as práticas escolares relacionam-se diretamente com os usos, as técnicas, os sentidos construídos nessa rede de relações sociais em um determinado momento histórico e político, no qual esse currículo está inserido. 
As narrativas das práticas das professoras me permitem desinvibilizar o que se passa nas escolas, compreender e trazer evidências de que nós vamos, aos poucos e, às vezes bem depressa, até mesmo nos corredores da escola, trocando nossas "descobertas", graças aos diversos saberesfazeres que estão sempre presentes, articulando-os entre si, criando novos e múltiplos conhecimentos. Tanto nas táticas desenvolvidas por professoras e professores, alunos e alunas, quanto nos usos que esses e essas fazem do que é aprendido na vida e nas escolas, sentimos os saberesfazeres cotidianos enredados aos outros diferentes saberesfazeres, incluídos ou não nas propostas oficiais.

Pensando nestas astúcias das professoras, quero acreditar, aposto que na artesania das práticas do currículo como criação cotidiana entram em cena as relações de sua produção, partilha e cooperação. Cada sujeito que compõe e tece o cotidiano escolar é único e apresenta capacidades e habilidades distintas, mas juntos e agindo em conjunto, ou seja, em cooperação mútua, tecem outros significados para suas práticas.

Nesta relação quero inserir a noção de que a participação e a solidariedade pautadas pelo princípio da comunidade (SANTOS, 1995, 2010), apontam as possibilidades de serem instauradas alternativas de trabalho cotidianas em que os sujeitos envolvidos exerçam uma não colonização do saber operado em cada grupo.

Por comunidade entendo não apenas o conjunto de pessoas num determinado território, mas sim o conjunto de ações, intenções e interações que as professoras buscam pôr em prática que Oliveira (2012) aponta como:

São totalidades complexas, que precisam ser ampliadas, precisam proliferar, se queremos superar os monopólios de interpretação do real herdados do cientificismo moderno ou a renúncia à interpretação, o seu outro, presente na aceitação acrítica de uma realidade e de uma ideologia de imobilização das lutas sociais, o que só é possível no diálogo entre saberes, valores e culturas. (p.17)

Para Santos (2006), a dimensão da participação direta envolvida na noção do princípio da comunidade trata do reconhecimento da limitação imposta por uma definição restrita do espaço político. A proposta de trazer esse novo senso comum em torno do político para além das questões envolvendo a representação política, assenta em evidenciar a possibilidade de "repolitização global da vida social" (SANTOS, 1995). Se por comunidade podemos entender um espaçotempo em que um ou mais grupos habitam submetidos a uma mesma regra em suas relações, podemos dizer que a microcomunidade instalada pelas professoras ao terem anunciado 


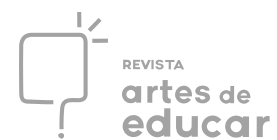

replanejarem o projeto de trânsito, exacerba a responsabilidade, à qual não podemos nos furtar, pautados pelo sentimento de pertencimento a um grupo, com o qual somos solidários e pelo bem-estar do qual somos responsáveis.

Por outro lado, nas relações que se estabelecem cotidianamente, posso também chamar as professoras de artífices, artesãs de práticas ordinárias. Aqui busco fazer uma analogia entre a atuação das professoras com o "artífice" identificado por Sennet (SENNET, 2012a) que aprende em e com suas artes de fazer, que abarcam a condição humana do engajamento, ou seja, pautadas pelo desejo de fazer bem o que se faz.

Sennet (2012a, 2012b) aponta que a artesania e a cooperação, enquanto práticas produzidas socialmente é fruto de demandas colocadas e que envolvem interação e diálogo. A capacidade de diálogo e de trabalho compartilhado denota os modos como os sujeitos se governam e se ligam uns aos outros, sendo inerentes a eles a perícia artesanal, a partilha e a construção coletiva, mesmo que para um produto individualizado.

Fazer é pensar, assim aponta Sennet, e o que as professoras/artífices fazem é reelaborar seus fazeres a partir de pensamentos que acreditam serem importantes. Para o autor, a relação entre fazer e pensar precisa ser tensionada, na medida em que a inquietude artesanal, a consciência e o engajamento, para a criação de um produto final, fazem da habilidade individual e coletiva, elementos que poderão também criar produtos para além do final previsto pela técnica.

No caso da pesquisa, a relação entre fazer e pensar evidencia como as professoras, artífices cotidianas de currículos, trabalham com as técnicas advindas de suas experiências pessoas, face às técnicas demandadas de forma prescritiva. O que está em jogo é a relação de permanente negociação dos sentidos das práticas, suas nuances entre o que está planejado e o que está praticado.

Profa. Fernanda: - Semana passada a Supervisora da minha escola veio nos dizer que o MEC está propondo o currículo único. Eu fiquei pensando como seria esse currículo pro Brasil todo?! Ela (a supervisora) foi passando os slides com o resumo das matérias e o que a gente deveria trabalhar, quando esse currículo for valer pra todo mundo, pois ele fala que todos têm direito de aprendizagem. Acho legal isso, eu mesma na época de escola tive problemas pra acompanhar as matérias, meu pai era militar e acabávamos mudando de cidade e toda vez que mudava tinha dificuldade em acompanhar a escola nova. Só que do mesmo jeito que o currículo vai ser igual pro Brasil todo eu acho que, da maneira como ela mostrou nos slides, algumas matérias estão fora de 
ordem. Acho que isso pode até vir pra gente como norma de trabalho, mas eu vou continuar fazendo o que acredito igual faço com o livro. Eu não sigo o livro à risca, ele fica lá no armário, prefiro ir montando as minhas aulas e o meu planejamento na medida em que vejo o avanço da turma, como ela foi no ano passado... Antes de começar a matéria sempre vejo com a professora do ano anterior até onde ela foi. Penso em tudo que já trabalhei, até mesmo pra não fazer igual todo ano, senão fica chato. Poxa, eu tenho 15 anos de sala de aula, acho que entendo bem como seguir com a matéria e agora vem um documento dizendo como tenho que trabalhar.

Ainda sobre a relação entre fazer e pensar, a fala da Fernanda nos provoca a pensar que, para além das dimensões normativas e propostas de textos curriculares, no espaço tempo macrossocial, as escolas possuem outras dimensões, micro, compostas por saberes locais, saberes da experiência e currículos que estão encarnados (NAJMANOVICH, 2001), pois constituem as ações dos praticantes nos seus saberesfazeres cotidianos, nas táticas com que enfrentam as estratégias do poder proprietário, como nos ensinou Certeau (1994).

Os modos de fazer, de criar e tecer o conhecimento são também reflexo da nossa vida, das nossas experiências. De maneira encarnada, as práticas fazem parte das nossas redes, afinal, a docência é uma das poucas profissões que são experienciadas desde a mais tenra idade. Ao longo da vida, o currículo e suas artes de fazer vão compondo nossas redes e "moldando" o uso que fazemos das orientações que recebemos.

O livro, a proposta didática e o texto curricular são os produtos impostos para serem consumidos, mas nas relações de uso, são incorporados, muitas vezes, de maneira contrária à original, ou seja, há uma invenção nas práticas do cotidiano que estabelecem as formas como professores e alunos, nas escolas, vão se ajustando e reorganizando o discurso oficial, o material oficial, criando uma produção mais cotidiana, tornada invisível, aquela dos 'consumidores', e que 'marca o que fazem com os produtos'.

Profa. Débora: - Isso que a Fernanda tá falando é muito importante, mas não é só porque o governo está querendo colocar um currículo único, mas é que todo dia, já há muito tempo sempre teve supervisor que ficou no nosso pé querendo que o planejamento fosse seguido igual tinha o documento, aquele amarelado... Meus deus, nunca tinha visto figura mais quadrada que nem a supervisora que tinha lá na escola. Se você fazia alguma coisa diferente do que ela tinha pensado, pronto era o fim. Tinha que fazer igual estava naquele papel mofado dela...era exposto $e$ ganhava medalha de ouro! 
Compreender o cotidiano escolar enquanto um espaçotempo de negociação de sentidos, fazeressaberes e conhecimentos sempre é algo desafiador, na medida em que isso possa representar um encontro com aquilo que nos é mais próximo, ou seja, nós mesmos, nossas práticas, nossas artes de lidar e relacionar com a alteridade e de enxergar os momentos de contradição e compreensão da importância de fazer deste espaçotempo local de solidariedade e de partilha e, porque não, de contradições.

Débora relata ter-se deparado com formas de legitimação curricular pautadas em propostas que, de certa maneira, significariam um engessamento de suas práticas. Assim é a vida escolar, permeada de noções e sujeitos que pensam de forma distinta, mais próximos do perfil monocultural da modernidade ou mais baseada numa proximidade com uma ecologia de saberes.

Sennet (2012a) aponta que muitas vezes os artífices são incompreendidos por suas formas distintas de trabalho. Aqui, com base no relato de Débora, ressalto também a maneira como o pensamento indolente, ortopédico, opera na criação de existências invisíveis. No entanto, apesar das amarras e situações de impasse que vivemos no cotidiano, o que fazemos permanentemente é recriar a vida, os conhecimentos, os valores, as crenças, modos de usar diferentes do instituído ou dos manuais, encontrando saídas para as situações que se apresentam.

Buscar nas práticas e suas narrativas como os currículos pensadospraticados e suas interfaces com o contexto de influência, dos textos e das práticas, propostos por Ball (2001), é perceber que o cotidiano escolar se configura como um espaçotempo de ampla diversidade epistemológica. Diversidade muitas vezes tornada invisível e massificada diante de inúmeras propostas prescritivas de programas didáticos desenvolvidos, notadamente, no contexto de textos oficiais.

Neste ínterim, sigo com meu mergulho no campo, dando continuidade ao que proponho pesquisar com o cotidiano escolar, compreendendo-o como rede de múltiplos saberesfazeres e de enunciação de uma ecologia de saberes. Santos (2008, p.33) esclarece que "o lugar de enunciação da ecologia de saberes são todos os lugares onde o saber é convocado a converter-se em experiência transformadora", ou seja, sentir o contexto das práticas curriculares das professoras como local onde o saber torna-se fazer, e vice-versa.

\section{Para um futuro vivenciado no presente}


Mergulhar no contexto das práticas é aliar-me à noção de que a ecologia de saberes é também oriunda de todos os lugares que estão para além do saber enquanto prática social separada (SANTOS, 2010), sendo necessário levar em consideração a influência das experiências, das crenças e dos modos de vida individuais e coletivos de cada professora e dos demais membros da comunidade escolar.

Pensar na constituição de micropolíticas de currículos enquanto invenção do cotidiano, tecidas por seus praticantes artífices, reporta-me a Ferraço (2008) quando afirma que só é possível pensar a questão curricular referenciada na dimensão das redes coletivas de fazeressaberes dos sujeitos que praticam o cotidiano.

Para Ferraço, a função social e política da escola e do currículo consistem em ampliar o horizonte das possibilidades de conhecimento, e no meu entendimento implica em ampliar também os currículos pensadospraticados existentes, tornados invisíveis. Afinal os currículos cotidianos, e suas micropolíticas, são processadas pelas redes de sujeitos com compõem e tecem o cotidiano escolar.

Portanto, quando as professoras relatam a apresentação de propostas curriculares prescritivas, estas não representam nada além do que formalidades, muitas vezes bricoladas, nas quais os conteúdos e métodos propostos passam a ter algum significado, ou não, quando "são lidos, discutidos, ensinados e enredados pelos sujeitos" (FERRAÇO, 2008, p.32).

Por opção política-epistemológica-pedagógica afirmo que minha ênfase investigativa está no local, na parte, no fragmento, que nunca é demais lembrar, contém o todo (MORIN, 2005). Nessa dimensão do social que quero pôr em destaque, busco empoderar as professoras como artífices de modos de fazer currículos pensadospraticados no cotidiano escolar, bem como ainda tecelãs de micropolíticas invisibilizadas de currículos.

Pensar o cotidiano e erguê-lo à condição de espaçotempo privilegiado de produção de conhecimentos, crenças e valores, considerando-o de modo complexo, implica que sejamos críticos às práticas de políticas de homogeneização e padronização dos currículos pensadospraticados. Nesse entendimento, vale dizer da permanente necessidade de questionamento das políticas que propõem padronizar e homogeneizar nossas escolas, professoras e alunos sempre em busca da suposta possibilidade de controle da realidade escolar e, porque não dizer, em prol da busca pela "melhor qualidade" definida fora do espaçotempo escolar.

Os aspectos teóricos apresentados e as narrativas das conversas entre as professoras vêm auxiliando a interrogar a elaboração curricular cotidiana, permitindo que se pense no currículo como espaço de negociação, ambivalência e fronteira em que se encontram e dialogam 
diferentes culturas e experiências sociais. Diferentemente da ideia de fechamento e determinação, o currículo se revela como parcialidade, mutabilidade, criação e dinamismo, sendo a produção curricular entendida tanto como construção em embates quanto também como negociações políticas que se dão, não num espaço de elaboração consensual, mas por meio de projetos em disputa por uma hegemonia, ainda que provisória ou instável.

Considero, nos limites deste texto, que, talvez, a importância da pesquisa e do seu desenvolvimento inicial ecoa na virtude da contribuição que pode trazer à disputa pelo reconhecimento dos saberes dos professores, de suas experiências, memórias e histórias de vida. Encontro nos escritos de Arroyo (2011); quando este aponta que "é fácil constatar que essas disputas adquiriram tais dimensões que nas escolas temos o currículo oficial, com seu núcleo comum, disciplinado e em paralelo temos o currículo na prática" (p.16).

Tenho a ciência de que minhas reflexões apresentam alguns caminhos abertos, e levantam importantes questões no que tange os campos do currículo, escola e política curricular. Este texto é uma parcela de pesquisa, uma reflexão que está em desenvolvimento, assim, não apresenta resultados definitivos, mas busca compreender/pensar os modos como os currículos são criados e acontecem no cotidiano escolar.

Não obstante, sinto-me desafiado a estabelecer um fluxo interpretativo entre o micro e o macro, a encontrar uma medida onde nem o isolamento e nem a generalização reduzam o entendimento. Não sei ainda como fazer, desconheço o caminho, mas a experimentação é o meu norte, ou ainda meu sul, não sei...

\section{REFERÊNCIAS}

ALVES, Nilda; OLIVEIRA, Inês Barbosa de.(orgs.). Pesquisa nos/dos/com os cotidianos das escolas: sobre redes e saberes. Petrópolis: DPetAlli, 2008, p. 39-48.

ARROYO, Miguel. Currículo, territórios em disputa. 2. ed. Petrópolis: Vozes, 2011.

BALL, Stephen J. Diretrizes politicas globais e relações politicas locais em educação. Currículo sem Fronteiras, V.1, n. 2, p. 99-116, 2001.

CERTEAU, Michel de. A invenção do cotidiano 1: Artes de fazer. Petrópolis: Vozes, 1994.

FERRAÇO, Carlos Eduardo. Ensaio de uma metodologia efêmera ou sobre as várias maneiras de se sentir e inventar o cotidiano escolar. In: OLIVEIRA, Inês Barbosa de; ALVES, Nilda. Pesquisa nos/dos/com os cotidianos das escolas: sobre redes de saberes. 3. ed. Petrópolis: DP et Alii, 2008, p. 101-117. 
GONÇALVES, Rafael Marques. Currículos pensadospraticados no cotidiano escolar: negociações e tessituras. 77 f. Qualificação (Doutorado em Educação). Universidade do Estado do rio de Janeiro, 2016.

MORIN, Edgar. Ciência com consciência. Rio de Janeiro: Bertrand Brasil, 2005.

OLIVEIRA, Inês Barbosa de. Boaventura e a educação. Belo Horizonte: Autêntica, 2006. .; SGARBI, Paulo. Estudos do cotidiano e educação. Belo Horizonte: Autêntica, 2008.

SANTOS, Boaventura de Souza. Conhecimento prudente para uma vida decente. São Paulo: Cortez, 2004.

A gramática do tempo: para uma nova cultura política. 2. ed. São Paulo: Cortez, 2008.

Um Ocidente não-ocidentalista? A filosofia à venda, a douta ignorância e a aposta de Pascal. In.: SANTOS, Boaventura de Souza; MENESES, Maria Paulo. (orgs). Epistemologias do Sul. São Paulo: Cortez, 2010, p. 519-562.

PAIS, José Machado. Vida cotidiana. São Paulo: Cortez, 2003.

SENNET, Richard. O artífice. 3. ed. Rio de Janeiro: Record, 2012a.

Juntos: os rituais, os prazeres e política da cooperação. Rio de Janeiro: Record, 2012b.

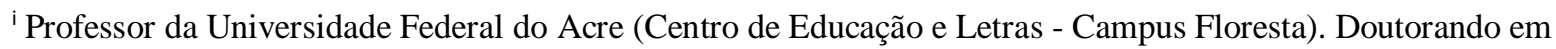
Educação pela UERJ/ProPEd. Líder do Grupo de Pesquisas em Memórias, Identidades, Currículos e Culturas GpMICC/CEL/UFAC. Membro do GT 12-Currículo da ANPEd e da Associação Brasileira de Currículo - AbdC. Bolsista CAPES. E-mail: rafamg02@gmail.com

ii A pesquisa foi desenvolvida com um grupo de professoras da Rede Municipal de Ensino da cidade de Três Rios, interior do estado do Rio de Janeiro.

iii Secretaria de Educação.

iv A tradução do francês, "homme ordinaire" seria mais apropriadamente feita para homem comum, considerando que é a ele que Certeau se refere, nada tendo a ver com o uso do termo ordinário em português coloquial.
} 